\title{
ENVOLVIMENTO DOS FIÉIS NO DISCURSO RELIGIOSO MIDIÁTICO: A SUBJETIVIDADE DÊITICA NA LINGUAGEM POR MEIO DO "VOCÊ"
}

RESUMO: 0 nosso objetivo neste trabalho é estudar a subjetividade dêitica empregada por pastores midiáticos para envolver 0 auditório por meio do pronome "você", a fim de prender-lhe a atenção. Justifica-se a escolha do tema devido à forte presença do discurso religioso nos meios digitais, especialmente em redes sociais e plataformas de publicação de vídeos e imagens. Para realizar a pesquisa, elegemos como objeto de pesquisa 0 gênero textual oral pregação. Para análise, elencamos como corpus quatro pregações evangélicas publicadas na internet. Verificamos que os recursos linguístico-textuais dêiticos empregados no discurso religioso representam uma forma de envolver 0 auditório à interação, fazendo-0 se sentir valorizado.

PALAVRAS-CHAVE: Discurso religioso; Envolvimento; Recursos linguístico-textuais.

\section{INVOLVEMENT OF THE FAITHFUL IN MEDIA-BROADCASTED RELIGIOUS DISCOURSES: DEICTIC SUBJECTIVITY IN 'YOU'-ADDRESSED LANGUAGE}

\begin{abstract}
Deictic subjectivity used by mediatic Protestant pastors to involve the audience by using the pronoun 'You' to capture their attention, is analyzed. The above provides a deep presence of religious discourse in the digital media, especially in social networks and in platforms for videos and images. The oral textual genre 'preaching' is the object of current research. Results show that deictic linguistic and textual resources used in religious discourse are a way to involve the audience with interactivity by valorizing it.
\end{abstract}

KEYWORDS: Religious discourse; Involvement; Linguistic-textual resources.

"Exporia ante ele a minha causa, e a minha boca encheria de argumentos". (Jó 23:4)

\section{INTRODUÇÃO}

Vivenciamos um fenômeno de evangelização favorecida pelas mídias, especialmente pela internet e pela televisão, de modo que é cada vez maior a importância e a influência que 0 discurso religioso evangélico tem exercido na sociedade brasileira, haja vista 0 aumento do número de fiéis que se declararam evangélicos no censo 2010 (IBGE, 2012). Ademais, houve crescimento exponencial do número de igrejas evangélicas no Brasil, da quantidade de redes de televisão cujos proprietários são pastores evangélicos e do número de programas evangélicos de rádio e televisão.

Por isso, é importante analisar o discurso religioso midiático, a fim de caracterizá-lo para melhor compreender as estratégias argumentativas que fazem esse discurso ser aceito e disseminado. Silva e Dias (2010, p. 81-82) corroboram essa perspectiva ao afirmarem que

Doutora e mestre em Estudos da Linguagem pela Universidade Estadual de Londrina (UEL). Docente da Universidade Estadual do Norte do Paraná (UENP), campus de Cornélio Procópio, PR. Docente do Programa de Pós-graduação em Ensino (PPGEN) e do Mestrado em Letras (ProfLetras), pela Universidade Estadual do Norte do Paraná (UENP). Brasil. E-mail: leticiajstorto@gmail.com 
Com o crescimento numérico do povo evangélico-protestante, a hegemonia católica foi ameaçada. Assim, a cultura brasileira, sempre ligada ao romanismo, tende a sofrer mudanças com a presença influente desse outro discurso religioso que ganha cada vez mais adeptos. Entender esse outro discurso religioso paralelo e ora contrastante com 0 discurso católico é necessário para se entender a efervescência religiosa por que, à semelhança de outros países sulamericanos, passa o Brasil.

Assim, o objetivo deste trabalho é analisar alguns recursos linguístico-discursivos de subjetividade dêitica empregados por pastores para envolver 0 auditório, prendendo-Ihe a atenção. Mais especificamente, estudamos a utilização argumentativa do "você" no discurso religioso de cunho evangélico. Para tanto, elegemos como objeto de pesquisa 0 gênero textual oral pregação. Para análise, elencamos como corpus quatro pregações publicadas e divulgadas na internet no site de vídeos YouTube. Os textos estudados foram escolhidos após pesquisa na plataforma do site por meio das palavras-chave "pregação evangélica". Com milhares de resultados, selecionamos os primeiros quatro vídeos com mais de 10 mil curtidas e que tivessem sido produzidos a partir de 2010. Como fundamentação, recorremos aos trabalhos da linguística textual e de outros autores que complementam a perspectiva teórica.

No que tange à metodologia, de acordo com os procedimentos técnicos utilizados, tratase de uma pesquisa documental e bibliográfica: a primeira porque 0 trabalho tem como fonte documentos, no caso gravações, cujos conteúdos não tiveram ainda tratamento analítico e ainda são matéria-prima de investigação e análise (SEVERINO, 2007); a segunda porque 0 estudo de pesquisas anteriores foi empregado como técnica auxiliar na análise do material adotado e na compreensão dos fenômenos observados.

Os critérios empregados para a seleção dos vídeos foram: I) ordem em que aparecem nos resultados da pesquisa na página eletrônica do YouTube; II) qualidade da gravação em termos de áudio e vídeo; III) quantidade de acessos e visualizações e/ ou de comentários dos internautas; IV) integridade na apresentação das pregações, ou seja, que elas estivessem preferencialmente completas. Os tópicos e os locais onde ocorreram as pregações não foram usados como critérios para a inclusão ou exclusão de um vídeo. Assim, o corpusé formado por pregações que versam a respeito de distintos tópicos e que ocorreram em diferentes locais, não necessariamente uma igreja, tampouco a sede da igreja a que cada pastor pertence. As pregações foram proferidas a partir de 2010.

As pregações foram transcritas grafematicamente ${ }^{2}$ conforme as recomendações do projeto NURC/SP (PRETI, 2005) e foram coletadas diretamente da página <https://www.youtube.com/>, de que foram baixadas e gravadas no computador para, em seguida, serem transcritas.

$\mathrm{Na}$ sequência deste texto, discutimos os aspectos teóricos a respeito de argumentação e subjetividade; em seguida, tecemos 0 estudo dos dados coletados.

\subsection{ARGUMENTAI!}

Argumentação vem do latim argumentatio, cujo tema (argu-) significa fazer brilhar, cintilar, iluminar. Assim, a argumentação é tudo aquilo que ilumina, que leva à compreensão e/ou percepção de uma ideia ou conceito. Ela é um elemento básico de constituição do discurso e tem sido estudada há muito tempo, desde a Grécia antiga pelos filósofos gregos. Nesse período, era apreciada como retórica, ou seja, a arte do bem falar, da erudição, da oratória e tinha como objetivo convencer e persuadir. Na época, Aristóteles (2005) teceu distinções entre as seguintes fases na

\footnotetext{
As transcrições podem ser: fonéticas (ênfase aos sons produzidos, utilizam-se, para isso, símbolos fonéticos); grafemáticas (utilizam-se grafemas para representar a língua falada; ênfase no como e no quê é dito; são mantidas marcas da oralidade; não se utilizam as convenções da língua escrita corrente, como uso normatizado de sinais de pontuação e outros); ortográficas (uso das convenções da escrita, tais como sinais de pontuação; elimina-se a maior parte das marcas de oralidade; ênfase no quê é dito; transcrição tipicamente utilizada em revistas e jornais).
} 
elaboração do discurso argumentativo (ou retórico):

- inventio (invenção) - constituição de argumentos e ideias para orientar o discurso;

- dispositio (disposição) - escolha e ordenação dos argumentos;

- elocutio (elocução) - exposição do discurso de modo claro e adequado. A argumentação focou, durante algum tempo, sua atenção nessa etapa;

- actio (ação) - enunciação oral do discurso, incluindo recursos não verbais, como gestos, meneios de cabeça, mímica etc., e prosódicos ou suprassegmentais, como pausa, entonação, ritmo etc.;

- $\quad$ memoria (memória) - retenção das informações para o desenvolvimento dos argumentos.

Depois de passar por fases de declínio, renovados, os estudos da argumentação ressurgem no século XX. Com isso, a argumentação foi o objeto linguístico de estudos da década de 1970/1980, favorecendo o surgimento de disciplinas que se preocupam basicamente com essa questão, como a semântica argumentativa e as teorias da argumentação na língua.

Segundo Perelman e Olbrechts-Tyteca (2005, p. 04), a argumentação "é o estudo das técnicas discursivas que permitem provocar ou aumentar a adesão dos espíritos às teses que se Ihes apresentam ao assentimento" (grifos dos autores); logo, devemos considerar a adesão dos espíritos o principal objetivo da argumentação. Declerq (1992), por seu turno, afirma que a argumentação é a transferência de valores inicialmente admitidos a outros, não se tratando de assentimento (aceitação), mas de substituição, de mudança de convicções. Nisso está, para 0 autor, a persuasão, que é também alcançada por meio de um trabalho linguístico-discursivo. Também, fazem parte dos recursos argumentativos os elementos paralinguísticos e suprassegmentais, os quais, na interação, corroboram a persuasão dos envolvidos. Assim, ao argumentar, o locutor emprega diferentes fatores de ordem linguístico-discursiva, imagéticos, prosódicos, gestuais e outros; portanto, trata-se de uma multissemiose de elementos envolvidos no ato de harmonizar os espíritos.

Por meio das marcas deixadas no discurso pelo locutor, podemos conhecer seus pontos de vista, suas atitudes e posicionamentos, mesmo que não sejam revelados explicitamente. Podemos, ainda, reforçar ou atenuar aquilo que dizemos. Para que isso aconteça, os discursos são constituídos de marcas da argumentatividade, que são, entre outras, as pressuposições, os índices de intenção, os modalizadores, os operadores argumentativos, as imagens do locutor/interlocutor/discurso que se constroem na interação (KOCH, 2011, p. 33).

\section{SUBJETIVIDADE E ARGUMENTAÇÃO}

A subjetividade é um recurso argumentativo que diz respeito à inscrição do sujeito no discurso e ao estabelecimento da relação com o outro, ou seja, às marcas (sempre existentes) da presença dos interlocutores no enunciado, 0 qual parte de alguém para outro alguém. Assim, toda subjetividade é uma intersubjetividade, já que 0 sujeito não existe por si só, ele só se define em face do outro. Pode-se, logo, afirmar que todo texto/discurso é subjetivo e intersubjetivo, "por que as palavras são recortes do mundo referencial e Ihe impõem uma forma particular de conteúdo" (CARVALH0, 1996, p. 36). Desse modo, subjetividade relaciona-se à

Emergência do eu no seio da linguagem, ou seja. [...] 0 eu fundamenta a consciência de si e esta, como se viu, dá-se no contraste com 0 tu. Assim, a subjetividade nasce no seio da intersubjetividade. Esses aspectos vão se tornar relevantes no tratamento do texto quando se observar o funciona- 
mento dos dêiticos (este, aqui, agora, hoje etc.) sejam de lugar, tempo, pessoa ou mesmo a modalidade e os tempos verbais. (MARCUSCHI, 2008, p. 71).

A subjetividade divide-se em dêitica e afetiva (ou avaliativa). Segundo Marcuschi (2008), os dêiticos, podem ser pessoais, temporais ou espaciais. Os primeiros referemse às marcas de pessoas do texto, 0 locutor e 0 interlocutor, utilizando, para isso, de nomes/ locuções nominais ("João", "pai", "meu filho", "meu irmão" etc.), de pronomes/locuções pronominais de primeira e segunda pessoa ("eu", "tu", "você"), de pronomes/locuções pronominais possessivos ("meu”, "teu", "seu” etc.) e de verbos/ locuções verbais de primeira ("ando", "cantei", "comi" etc.) e segunda pessoa ("andas", "cantais", "comestes" etc.). Esses elementos são marcas da subjetividade dêitica porque apontam as pessoas do discurso, ou seja, o locutor e o interlocutor (aquele que diz e aquele para quem ele diz). Os dêiticos temporais, por sua vez, referem-se às marcas de tempo, empregadas nos verbos e nos advérbios/locuções adverbiais/orações adverbiais ("ontem", "depois de hoje", "quando nevar", e muitos outros). Já os dêiticos espaciais relacionam-se ao uso de advérbios/locuções adverbiais de lugar ("aqui", "lá", "embaixo" etc.) e de pronomes demonstrativos ("esse", "esta", "aquilo" e variações), referem-se às marcas de lugar no enunciado (e na enunciação). Benites (2001) afirma que 0 advérbio, quando nominal, reflete a mesma subjetividade do adjetivo; quando pronominal, faz menção ao tempo e ao lugar da enunciação, ambos definidos e delimitados pelo sujeito do discurso. Assim, os advérbios também marcam a subjetividade dêitica do texto.

A subjetividade afetiva é aquela na qual 0 enunciador coloca a sua avaliação pessoal, expressa os seus sentimentos, pois "nenhum falante descreve a natureza com imparcialidade absoluta; mesmo que se imagine neutro, é obrigado de alguma forma a imprimir sua interpretação" (CARVALHO, 1996, p. 36).

De acordo com o Dicionário de lingüística $e$ gramática, de Mattoso Camara (CAMARA JUNIOR, 2007, p.49), a afetividade diz respeito à "capacidade - a) de exprimir o falante na linguagem os sentimentos de simpatia, entusiasmo ou repulsa que lhe despertam as idéias enunciadas, bem como - b) de despertar, nos ouvintes, análogos sentimentos". Entre outros recursos, a subjetividade afetiva se reflete em

- Artigos: definidos (texto mais concreto, elementos mais familiarizados ou notórios dos interlocutores) e indefinidos (texto mais abstrato, apresentando mais imprecisão, conhecimento não compartilhado ou novidade).

- Adjetivos: os adjetivos são os elementos gramaticais mais afetivos, eles demonstram a relação subjetiva entre 0 locutor e 0 referente e 0 interlocutor, marca também 0 engajamento afetivo do locutor (julgamento ou apreciação) em relação ao que enuncia.

- Figuras de linguagem (ou figuras de retórica, figuras retóricas): refletem 0 emocional do locutor perante aquilo que está dizendo. Segundo Guimarães (2004), as figuras são um modo especial, diferente, de falar, tratase de um modo que se distancia daquele considerado "normal", objetivando causar um "estranhamento" no interlocutor, uma surpresa, chamando-Ihe a atenção.

- Modalizadores: quase todos os advérbios, em especial os de modo, são afetivos (exceção: advérbios de tempo e de espaço, pois são dêiticos); modalizar significa avaliar.

- Exclamação e interjeição: apresentam, claramente, o sentimento do locutor diante de algo, servindo para indicar emoções, estados emocionais.

- Intensificadores: os advérbios de intensidade e as figuras de linguagem de repetição são intensificadores, funcionando para aumentar 
a força ilocutória dos enunciados, isto é, aumentam a carga semântica daquilo que é dito no discurso.

- Comparadores: em especial a conjunção subordinativa comparativa "como", funcionam para tecer comparações, que implicitamente marcam a orientação argumentativa do discurso.

- Sufixo diminutivo: de caráter depreciativo ou, ao contrário, apreciativo. Além disso, indica ironia ou familiaridade do enunciador diante daquilo que enuncia.

0 Quadro 1 que segue resume os recursos linguísticos de subjetividade.

Quadro 1. Recursos linguísticos de subjetividade

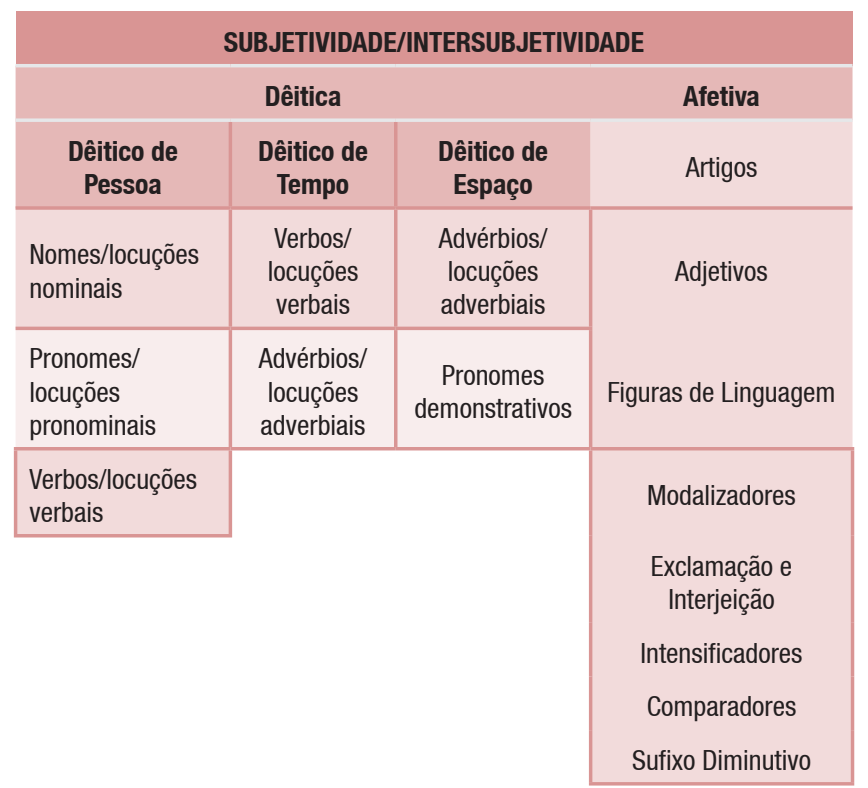

Fonte: Dados da pesquisa.

Os chamamentos (invocação), elementos utilizados para atrair/interpelar 0 interlocutor, são, geralmente, representados por nomes/locuções nominais e por pronomes, como se pode perceber na análise que segue.

\section{3 "VOCÊ" Aí: A SUBJETIVIDADE NO DISCURSO RELIGIOSO}

A invocação é fator importante no discurso religioso e se reflete no emprego de nomes e pronomes que os pastores usam para se dirigir ao auditório e para clamar à Trindade Santa (Deus Pai, Filho e Espírito Santo). Trata-se, segundo Perelman e OlbrechtsTyteca $(2005)^{3}$, de uma figura de comunhão, cujo objetivo é justamente criar ou aumentar a comunhão do falante com 0 auditório. Por meio da invocação, 0 locutor empenha-se em buscar a participação ativa dos ouvintes (PERELMAN; OLBRECHTS-TYTECA, 2005).

Em relação aos grupos de interlocutores, notamos que, para se referir ao auditório, os pastores, em geral, empregam vocativos afetivos; e para a referência à Trindade, vocativos respeitosos (Senhor) ou afetivos (Pai).

Quadro 2. Vocativos empregados pelos pastores no corpus analisado

\begin{tabular}{|c|c|c|c|c|}
\hline & Pregação 1 & Pregação 1 & Pregação 1 & Pregação 1 \\
\hline 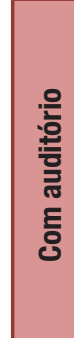 & $\begin{array}{l}\text { Você/Cê (s) } \\
\text { Pessoal } \\
\text { Meu amigo, } \\
\text { minha } \\
\text { amiga }\end{array}$ & \begin{tabular}{|l} 
Você/Cê (s) \\
Amigo(s), \\
amiga(s) \\
Irmão, irmã \\
Meu irmão \\
Meu \\
irmãozinho
\end{tabular} & \begin{tabular}{|l} 
Você/Cê (s) \\
Meus irmãos \\
Meus \\
amados \\
irmãos \\
Meu irmão, \\
minha irmã \\
Meu filho \\
Meu querido
\end{tabular} & \begin{tabular}{|l} 
Você/Cê (s) \\
Filhinho, \\
Filhinha \\
Meu irmão \\
Igreja
\end{tabular} \\
\hline
\end{tabular}

Fonte: Dados da pesquisa.

0 vocativo com valor afetivo imprime sentimentalismo e aproximação no discurso. Segundo Castilho (2010, p. 479), o pronome pessoal "você" estabelece essa proximidade, pois relaciona iguais: "você passou a ser no PB [português brasileiro] um tratamento de igual para igual" (grifo do autor). Assim, os pastores mostram-se próximos, íntimos dos fiéis, que não são apenas seus irmãos na fé, mas seus queridos irmãos. Isso gera empatia e simpatia no auditório, que pode se comover com esse contexto

Para se referir a esse recurso, os autores utilizam as seguintes nomenclaturas: "apóstrofe" e "interrogação oratória". 
mais envolvente, acolhedor. A mensagem implícita que ele pode entender é: fiel, és uma pessoa querida para nós (da igreja, dessa comunidade), que temos em ti um irmão amado com quem nos preocupamos, a quem queremos bem, por quem oramos e intercedemos.

Assim, o emprego do "você" é um dos principais responsáveis pela criação desse ambiente de proximidade, já que o pronome é utilizado entre falantes que se conhecem ou que desejam estreitar relações. Por outro lado, ele pode, implicitamente, mostrar a hierarquia que há entre os interlocutores, já que o pastor chama os fiéis de "você", mas esses, geralmente, chamam-no de senhor ou mesmo de pastor e demais nomenclaturas que cada comunidade utiliza, como: bispo, sumo-sacerdote, missionário, apóstolo e outros.

A pregação com maior incidência do pronome "você" (cê) para se referir ao auditório (61 ocorrências) foi a primeira. Em contrapartida, na quarta pregação analisada, menos se empregou (apenas 10 ocorrências) esse recurso, pois seu locutor preferiu vocativos mais afetivos (p. ex.: irmãozinho). Em geral, nos textos observados, o pronome foi empregado no singular, as ocorrências no plural foram pouco representativas (apenas $4 \%$ do total).

Quadro 3. Pronome você/cê(s) nos textos estudados

\begin{tabular}{|l|c|c|}
\cline { 2 - 3 } \multicolumn{1}{c|}{} & VOCÊ/CÊ & VOCÊS/CÊS \\
\hline PREGAÇÃ0 1 & $65(96 \%)$ & $03(4 \%)$ \\
\hline PREGAÇÃO 2 & $40(100 \%)$ & -- \\
\hline PREGAÇÃO 3 & $48(100 \%)$ & -- \\
\hline PREGAÇÃO 4 & $11(79 \%)$ & $03(21 \%)$ \\
\hline Total & $159(96 \%)$ & $06(4 \%)$ \\
\hline
\end{tabular}

Fonte: Dados da pesquisa.

A maior incidência do emprego desse pronome de valor referencial indica a busca por envolver 0 auditório, trazê-lo para o discurso, direcioná-lo a ele, a fim de, por conseguinte, angariar a sua adesão. Além do mais, o uso acentuado de pronome que individualiza 0 ser denota a particularidade que 0 indivíduo como ser único adquire nesse discurso, em que o fiel se sente valorizado, enaltecido, de modo que se persuada mais facilmente. Com a particularização do ser, o locutor dispara a mensagem de que, naquela comunidade, cada pessoa é de fato vista e valorizada como única, insubstituível, pois a pessoa é valorizada pelo que é, e não pelo conjunto a que ela pertence, de forma que ela adquire para 0 grupo um valor imensurável, não podendo ser trocada por outra pessoa. É assim que 0 fiel pode ser sentir quando o pastor fala diretamente para ele, não para o todo. Além do mais, com 0 emprego dos pronomes na segunda pessoa do singular (ainda que a priori o termo funcionasse como pronome de tratamento, hoje ele é empregado no papel de pronome pessoal de terceira pessoa), o discurso se volta diretamente ao interlocutor, que o toma para si: nossa, ele (o pastor) está falando comigo, isso é para mim. Com tais elementos, além do consequente convencimento, angaria-se a atenção do público, que precisa estar atento às palavras, porque elas são ditas a ele, não ao colega ao lado. Apesar disso, o fiel, ainda que valorizado na sua individualidade, faz parte daquele todo que forma a igreja. Está nisso outra oposição do discurso religioso: indivíduo x coletividade.

Quadro 4. Oposições causadas pelo uso de você versus vocês no discurso religioso

\begin{tabular}{|c|c|c|}
\hline \multirow{2}{*}{ VOCÊ/CÊ } & \multirow{2}{*}{$\mathbf{X}$} & VOCÊS/CÊS \\
\cline { 1 - 1 } $\begin{array}{c}\text { Individual } \\
\text { Igualdade }\end{array}$ & $\begin{array}{c}\text { Coletivo } \\
\text { Superioridade }\end{array}$ \\
\hline
\end{tabular}

Fonte: Dados da pesquisa.

0 excerto que segue mostra a participação ativa dos fiéis em uma interação assimétrica, ou seja, naquela em que o domínio da palavra é dado a alguém, no caso ao pastor. Apesar de o pastor ser quem regula a interação, os seus interlocutores não são impedidos de participarem com e sem tomada de turno (intervenção do interlocutor, vez de fala) da situação de fala. No trecho, verificamos que os fiéis são "convidados" a participar da pregação. Com certeza, 
para os envolvidos na interação, esse chamamento contribui para envolver e emocionar 0 auditório, que, por se sentir parte daquele grupo, daquele culto, torna-se mais vulnerável a aceitar o discurso do outro (o pastor) e, no caso, sua igreja. No exemplo, grifamos os dêiticos pessoais representados por pronomes de segunda pessoa discursiva (aqueles que se referem aos fiéis).

\section{EXCERTO 1}

LOCUTOR: [[...]]controle a an::siedade... um pouco de ansiedade... é fenomenal... faz você ser dinâmico... faz você usar a sua mente a sua imaginação... faz você correr atrás... faz você lutar... agora... uma PRE::OCUPAÇÃO... EX-CES-SI-VA... e essa que é a ansiedade... e-xa-cer-ba-da... é uma preocu-pa-ção excessiva... que é... sintoma de medo... essa ansiedade... é uma sen-sa-ção des-con-fortan-te... de sofrimento e apreensão... ligado... a um acontecimento que ainda não aconteceu... é isso aqui que é ansiedade... sabe o que que ela faz?... essa ansiedade "()... não pode passar de hoje... sangue de Jesus tem poder o coração tá aqui na boca pastor 0 coração tá bam bam bam bam tá pela boca... ((simula mal estar))... não tô conseguindo res/respirar"... sudorese... ((simula respiração acelerada)) "ai... vou morrer"... ((pausa longa)) cê sabe o que que essa ansiedade produz?... um tremendo impacto no teu cérebro... ocasionando... deformações químicas $e$ físicas... cêe sabe o que que essa ansiedade produz?... faz você ver SÓ... o que vai dar ERRADO... e NUNCA o que dá certo... ((pausa)) [[...]]

PREGAÇÃO 3 - L. 102-115

No trecho, o falante focaliza o seu interlocutor, o que pode ser observado pela reiteração do pronome "você". Com isso, ele chama a atenção do auditório, que passa a receber a mensagem com teor particularizado, é um efeito de chamamento, de convocação a aceitar aquela palavra como sendo, para 0 fiel. Observamos que todas as ocorrências de "você" estão no singular, de modo que 0 interlocutor do discurso sente que a mensagem é diretamente destinada a ele, o que aumenta 0 teor argumentativo e afetivo do discurso.
Além do uso de pronomes, há também outros recursos de subjetividade, como verbos no imperativo ("controle a an::siedade... um pouco de ansiedade...é fenomenal... "), discurso indireto livre, em que o falante recorre à fala do seu interlocutor para enfatizar e teatralizar 0 que diz: "essa ansiedade '[...] não pode passar de hoje... sangue de Jesus tem poder o coração tá aqui na boca pastor 0 coração tá bam bam bam bam tá pela boca... ((simula mal estar))... não tô conseguindo res/ respirar'... sudorese... ((simula respiração acelerada)) 'ai... vou morrer'...".

A título de exemplo, segue um excerto em que o locutor também se utiliza, além de nomes e pronomes, de outros recursos para envolver o auditório, corroborando sua persuasão e envolvimento.

\section{EXCERTO 2}

LOCUTOR: [[...]] óh pessoal... quando você vier aqui na frente... por favor não venha como se estivesse carregando um caixão... nem venha... como se estivesse seguindo uma procissão... venha com raiva... venha com ódio... venha... revoltado... porque... a sua maneira de expressar... quando você vem aqui na... frente... mostra... como vai ser o seu futuro... mostra como você vai atingir o seu objetivo... porque... o... a conquista que você quer... depende da sua fé... depende da sua convicção... depende da cer::teza que há dentro do seu peito... é assim que funciona... não é uma religiosidade... não é... não é:.... caretice... você tem que... vocêe tem que expressar essa... essa... esse ARROJO... essa CORAGEM... você não pode ser religioso... você não pode ser religioso jamais... porque se não você vai perder... você vai ficar enganado... vocêe vai lu/... ficar o resto da sua vida na igreja e não vai acontecer nada... você tem que mudar a maneira de agir... você tem que... você tem que... fazer algo diferente... você tem que PENSAR diferente... porque se você não fizer alguma coisa diferente NADA vai acontecer de diferente na sua vida... ou vai? [[...]]

PREGAÇÃO 1 - L. 1-13 
Notamos o emprego de verbos no imperativo ("não venha", "nem venha", "venha", "mostra", "não pode" etc.), de nomes ("pessoal") e pronomes ("você" 16x). ademais, há recursos suprassegmentais, como pausas (representadas pelas reticências) e elevação do tom de voz (marcada pela caixa alta). Por meio desses recursos, o locutor envolve os fiéis, prende a sua atenção, faz com que eles ouçam aquilo que é dito, façam o que Ihes é solicitado, reforcem sua fé.

Enfim, a invocação e os demais recursos colaboram para 0 envolvimento dos fiéis, para prender-Ihes a atenção, trazê-los para 0 discurso, com a finalidade última de convencê-los, convertêlos.

\section{CONCLUSÃO}

0 discurso religioso midiático é bastante significativo e está muito presente na sociedade contemporânea, na qual interfere de diferentes maneiras, colabora para a construção de sentidos, a organização das comunidades, a produção de saberes, entre outros. Nesse contexto, o discurso evangélico, especialmente 0 de cunho Pentecostal, tem se sobressaído. Como dito antes, isso tudo é reflexo do (e é refletido no) aumento expressivo de brasileiros que se autodeclararam evangélicos no último Censo (IBGE, 2012) e no "boom das mídias evangélicas", fenômeno que marca a expansão massiva que as mídias evangélicas tiveram nos anos 1990.

Assim, por se tratar de um discurso que se quer envolvente e, por conseguinte, persuasivo, nas pregações as marcas de intersubjetividade são abundantes, porque favorecem 0 engajamento dos interlocutores, de modo que eles se sintam parte do grupo e, ao mesmo tempo, importantes como seres únicos que são. Por isso, verificamos que a utilização de nomes e pronomes pessoais como recursos linguísticos de subjetividade argumentativa é muito recorrente no discurso religioso midiático, que se apresenta como sendo altamente persuasivo.

Quanto à invocação, percebemos 0 uso recorrente de "você(s)" para a referência ao auditório. Com a utilização desse pronome, os falantes aproximam-se de seus ouvintes. Com o emprego do pronome no singular, o locutor particulariza seu alocutário, direciona o discurso a ele, de modo a envolvê-lo ainda mais, já que esse recurso argumentativo cria um ambiente de proximidade e de sedução. Isso se deu, principalmente, na primeira pregação; na quarta pregação houve menos ocorrências. Ademais, os vocativos usados na terceira pregação figuram entre os mais afetivos, como "meus amados", "meus queridos". Trata-se de um elemento argumentativo extremamente sedutor, posto que os interlocutores se sentem estimados, valorizados. Assim, também, na segunda e na quarta pregações, seus locutores empregam o diminutivo para chamar os fiéis, "irmãozinho", "irmãzinha", criando um ambiente acolhedor, de intimidade e de proteção.

Para concluir podemos afirmar que o discurso religioso é altamente argumentativo, podendo ser considerado um dos discursos mais persuasivos, envolventes e sedutores que conhecemos.

\section{REFERÊNCIAS}

AFETIVIDADE. In. CAMARA JUNIOR, J. M. Dicionário de linguística e gramática: referente à língua portuguesa. 26. ed. Petrópolis, RJ: Vozes, 2007, p. 49.

ARISTÓTELES. Retórica. 2. ed. Lisboa, Portugal: Imprensa Nacional-Casa da Moeda, 2005. (Coleção Obras completas de Aristóteles, vol. VIII, tomo I).

BENITES, S.A.L. Leitura e análise linguística. In: SEMANA DE LETRAS, 5., Maringá, UEM. Anais... Maringá: EDUEM, 2001, p. 39-44.

CASTILHO, A. T. de. Gramática do português brasileiro. São Paulo: Contexto, 2010.

DECLERQ, G. L'art d'argumenter: structures rhétoriques et littéraires. Paris: Édition Universitaires, 1992.

DUCROT, 0. Provar e dizer: linguagem e lógica. Tradução de Tradução de Maria Aparecida Barbosa, Maria de Fátima G. Moreira e Cidmar Teodoro País. São 
Paulo: Global Universitária, 1981.

GUIMARÃES, E. Figuras de retórica e argumentação. In: MOSCA, Lineide do Lago Salvador (Org.). Retóricas de ontem e de hoje. 3. ed. São Paulo: Humanitas, 2004, p.17-54.

INSTITUTO BRASILEIRO DE GEOGRAFIA E ESTATÍSTICA - IBGE. Censo demográfico 2010: características gerais da população, religião e pessoas com deficiência. Rio de Janeiro: [s/n], 2012. (CD-ROM).

KOCH, I. G. V. Argumentação e linguagem. 13. ed. São Paulo: Cortez, 2011.

MARCUSCHI, L. A. Produção textual, análise de gêneros e compreensão. São Paulo: Parábola, 2008.

MOSCA, L.L.S. Velhas e novas retóricas: convergências e desdobramentos. In: MOSCA, L. L. S. (Org.). Retóricas de ontem e de hoje. 3. ed. São Paulo: Humanitas, 2004, p. 17-54.

PERELMAN, C.; OLBRECHTS-TYTECA, L. Tratado da argumentação: a nova retórica. Tradução de Maria Ermantina de Almeida Prado Galvão. 2. ed. São Paulo: Martins Fontes, 2005.

PRETI, D. (Org.). 0 discurso oral culto. 3. ed. São Paulo: Humanitas, 2005.

SEVERINO, A.J. Metodologia do trabalho científico. 23. ed. São Paulo: Cortez, 2007.

SILVA, É. C. da; DIAS, J. C. T. Uma pregação pentecostal. Paralelos, Universidade Católica de Pernambuco, v. 1, n. 1, p. 81-95, jan./jun. 2010.

Recebido em: 30/05/2018 Aceito em: 24/10/2018 